\title{
Late outcome of very severe blunt head trauma: a 10-15 year second follow-up
}

\author{
INGER VIBEKE THOMSEN \\ From Hospital of Physical Medicine, Hornbaek and Department of Neurology, Rigshospitalet, University \\ Hospital, Copenhagen, Denmark
}

SUMMARY Forty patients with very severe blunt head trauma (post-traumatic amnesia $\geqslant 1$ month) were initially examined at an average of 4.5 months after the injury. The patients were visited in their homes $2 \cdot 5$ years and 10-15 years after the accident and questionnaires were presented to patients, relatives and/or staff. Though physical impairment, dysarthria and defects of memory remained severe in many cases, the psychosocial sequelae presented the most serious problems. Permanent changes in personality and emotion were reported in two thirds and were especially frequent among the youngest patients. The worse overall outcome was seen in cases with severe brainstem involvement or anterior lesions or both. In spite of the great frequency of deficits long-term improvement of functional state was common and several regained at least some work capacity.

The majority of patients surviving very severe head trauma are young people. A few may have a rather satisfactory recovery, but most face disability for life.

Investigations on late outcome are few in number and vary in populations studied, criteria of outcome, and interval between trauma and assessment. ${ }^{1-3}$ In 1967 London $^{4}$ drew attention to the increasing number of severely disabled survivors of head injury. He emphasised the distressing effects of severe cerebral damage on the personality and the heavy burden imposed upon the family. Fahy $e t a^{2}$ found in a 6 year follow-up of a group of patients that few escaped permanent sequelae: recovery of motor dysfunction was generally good and eventual neurological residua were more easily tolerated by patients and relatives than psychiatric impairment, including dementia. At a follow-up 1 to 6 years after discharge from hospital, Najenson et $a^{3}$ described improvement in motor deficits, in functional state and, to a lesser extent, in intellectual functions.

Results of quantitative assessment ${ }^{5}$ as well as information based upon repeated structured interviews of close relatives during the first posttraumatic

Address for reprint requests: Dr IV Thomsen, Department of Neurology, Rigshospitalet, 2100 Copenhagen $\emptyset$, Denmark.

Received 30 July 1982 and in revised form 26 February 1983 Accepted 14 May 1983 year ${ }^{67}$ correspond with clinical findings. Daily living is primarily affected by impairment of personality and intellect and, to a lesser extent, by physical incapacity and disorders of communication. Emotional changes and disturbed behaviour are often serious problems to the relatives.

In the author's ${ }^{8}$ follow-up study of patients with severe head trauma the greater part suffered from loss of social contact and nearly all relatives complained of changes in personality and behaviour. At second follow-up (to be reported in this paper) the author aims to provide data on the late psychosocial outcome.

\section{Method}

\section{Patients}

Forty patients from an original group of $50^{*}: 28$ males and 12 females with severe blunt head trauma constituted the sample. The males were aged 15-44 years (mean 21.5) when injured, the females 15-44 years (mean 27.3). Seventeen were more aged than 21 years (mean 29.7) and 23 were 15-21 years (mean 18.5). Three were injured by falls, and 37 were victims of road traffic accidents. Half the men and nine women were involved in car accidents, nearly all the latter as front seat passengers. All were unconscious at the scene of disaster and by admission to hospital and remained so for days or weeks. The post-

* Of the remaining 10 , four had open brain injuries, three had not been visited, and three had died. They were all found dead in their apartments 4,11 and 12 years respectively after the trauma. 
Table 1 Types of lesions and length of PTA

\begin{tabular}{|c|c|c|c|c|}
\hline \multirow[t]{2}{*}{ Types of lesions } & \multicolumn{3}{|l|}{$P T A$} & \multirow{2}{*}{$\begin{array}{l}\text { Total no } \\
\text { patients }\end{array}$} \\
\hline & 1-2 months & 2-3 months & $>3$ months & \\
\hline $\begin{array}{l}\text { I.Closed head injury } \\
\text { II.Closed head injury with sions of brainstem }\end{array}$ & 1 & 3 & 5 & 9 \\
\hline $\begin{array}{l}\text { damage } \\
\text { III.Closed head injury with verified focal lesion }\end{array}$ & $\begin{array}{l}1 \\
1\end{array}$ & $\begin{array}{l}1 \\
6\end{array}$ & $\begin{array}{r}13 \\
9\end{array}$ & $\begin{array}{l}15 \\
16\end{array}$ \\
\hline
\end{tabular}

traumatic amnesia (PTA) was more than 3 months in 27 and no one had a PTA of less than one month (table 1). The sample is thus of very severely injured patients. There was no difference in PTA in the two age groups, that is, above or below 21 years (Mann Whitney rang sum test). The types of lesions are described in table 1 . Nineteen patients had skull fractures. Fifteen had signs of brainstem involvement (type II), and 16 patients with type III lesions (12 left and four right) had neurosurgical operations for removal of a haematoma except for two with depressed fractures. This type of lesion was most common among the young.

The patients came from all over Denmark and the majority were labourers or clerks. There were no grossly psychosocially maladjusted or obvious alcoholics in the series.

\section{Procedure}

The patients were initially examined by the author at an average of 4.5 months after the trauma, and were treated for months or years for their neuropsychological dysfunctions, especially those of communication. A follow-up examination $^{8}$ took place at least one year (on average 2.5 years) after the injury. The patients were readmitted to hospital and seen by a neurologist, a clinical psychologist and by the author, who also paid visits to the patients' homes, where a close relative was asked questions about the patient's physical and mental state, behaviour and self-care ability.

Between 10 and 15 years after the injury another visit by the author took place. An expanded questionnaire was presented to a relative (if possible the same one as before) or the staff at nursing homes, hospitals and/or work-shops. The patients were interviewed by a similar, but not identical questionnaire. When the two statements did not agree, the relative's or staff's answers were preferred. In some cases, in which there was no longer a close relative, only the patient's answers could be obtained. The patients were not admitted to hospital and assessment of cognitive functions did not take place. The results at the second followup are thus based on the information the author received in the homes.

\section{Results}

By means of these procedures, continuing disturbances in the following areas were examined (A) medical and demographic, (B) neuropsychological, and (C) psychosocial.

\section{A. Medical and demographic sequelae}

Place of living The place of living at the time of the first and second follow-up (2.5 and 10-15 years respectively) is shown in table 2 .

The greatest change during the interval was the number of single patients leaving their homes as a child. A few did so voluntarily, the remaining because they lost their father or mother. Nine were married at the first follow-up (one lived in a nursing home). At the second follow-up seven (two men and five women) had been divorced. They all had children. The two patients who remained married had no children. In the years between the examinations six had married, but two had divorced again. Two were cohabiting. At the second follow-up three were in nursing homes and one patient had spent the past eight years in an acute psychiatric ward.

Physical sequelae Motor impairment was initially present in all (table 3). At the first follow-up 10 had recovered, six from hemiparesis, one from hemiparesis and mild cerebellar symptoms, and three from bilateral spasticity. Of the remainder none was bedridden, but 12 had severe and five moderate symptoms. Cerebellar dysfunction was frequent, also among those with mild deficits. The physical status was unchanged at the second follow-up, except in one case in which cerebellar signs had become pronounced. Seven were confined to wheelchairs and six had severe ataxia and/or poor balance. Eleven had lesions with brainstem

Table 2 Place of living at first and second follow-up

\begin{tabular}{lcc}
\hline & $2 \cdot 5$ years & $10-15$ years \\
\hline Alone & 2 & 17 \\
Alone with child & 1 & 2 \\
With parent(s) & 24 & 9 \\
With spouse or partner & 8 & 8 \\
In hospital or nursing home & 5 & 4 \\
\hline
\end{tabular}

Table 3 Motor impairment

\begin{tabular}{lccc}
\hline & I. examination & 2.5 years & $10-15$ years \\
\hline Severe & 18 & 12 & 13 \\
Moderate & 7 & 5 & 4 \\
Mild & 15 & 13 & 13 \\
No symptoms & 0 & 10 & 10 \\
\hline
\end{tabular}


involvement (type II). With reference to age, seven were 21 years or less, when injured, and six were more than 21 .

At the first follow-up one patient had recovered from a II ${ }^{\text {nd }}$, two patients from a III ${ }^{\text {rd }}$, and one from a $\mathrm{VI}^{\text {th }}$ cranial nerve lesion. Severe visual impairment remained in four cases. Two had a $\mathrm{II}^{\text {nd }}+$ a $\mathrm{III}^{\text {rd }}$ nerve lesion, one a II ${ }^{\text {nd }}+$ a IV ${ }^{\text {th }}$, and one a III ${ }^{\text {rd }}$ cranial nerve lesion with bilateral ptosis. All had severe visual problems at the second follow-up. Hemianopia remained permanent in a further four patients and so did anosmia in two patients with no skull fractures.

Late epilepsy was reported in nine $(23 \%)$. The first attack occurred during the first year in four cases, in the remaining up to 11 years after the trauma. Seven had verified focal lesions (type III).

Psychiatric sequelae The frequency of posttraumatic psychoses can be seen in table 4. Early onset occurred in two cases. A 25-year-old man with a type I lesion including bilateral frontotemporal damage (permanent EEG findings) remained in a psychiatric hospital for five years. He presented no psychotic symptoms 12 years after the injury and was able to live alone. A 17 -year-old female patient with multiple fractures of the skull, especially in the anterior base and in the frontoorbital regions, became a schizophreniform psychotic in relation to surgical correction of the legs and remained so for several weeks. Her parents were killed in the accident and the patient spent many years in a nursing home. She had loss of sexual inhibition. At the second follow-up she was cohabiting with a much older man. It was not possible to establish a genuine emotional contact with her.
Late onset occurred in six cases. Two patients had permanent problems. One, a young woman with fractures in the frontal regions and a PTA of 5 months had a total loss of sexual inhibition and occasional fits of rage during which she attacked the staff in the psychiatric nursing home. The other, a man aged 22 years when injured had a type II lesion and a PTA of 4 months. He was referred to a psychiatric hospital two years after the trauma because of aggressive behaviour and fear of suicide attempts. He was an orphan and had no relatives. At the second follow-up he had stayed eight years in an acute psychiatric ward without any treatment at all. His severe left hemiparesis, severe dysarthria and dysphonia (trauma to larynx) remained. When interviewed the patient spontaneously said, "I am kept under lock and key and forgotten".

Eight patients $(20 \%)$ thus had posttraumatic psychoses. Five had signs of frontal and/or temporal damage. Six were below the age of 21 when injured. None of the patients had premorbidly been admitted to psychiatric departments.

Dependance At the first follow-up information from relatives as well as clinical observation indicated that 24 patients were dependant. Nine needed help with washing, dressing and eating and the remaining could not be left alone. At the second follow-up half the patients, including one with initial total dependance, were able to take care of themselves. Of the 12 patients who remained dependant, three were in nursing homes and one in a psychiatric hospital. All had difficulties in self-care as had a further eight patients of whom seven lived with their families and one in sheltered housing. Two had no motor deficits and two had mild motor symptoms.

Table 4 Post-traumatic psychoses

\begin{tabular}{|c|c|c|c|c|c|c|c|}
\hline Sex & $\begin{array}{l}\text { Age at } \\
\text { trauma } \\
\text { (yr) }\end{array}$ & $\begin{array}{l}\text { Type of } \\
\text { lesion }\end{array}$ & Total & $\begin{array}{l}\text { PTA } \\
\text { months }\end{array}$ & Onset & Duration & $\begin{array}{l}\text { Status at II. } \\
\text { follow-up }\end{array}$ \\
\hline m & 25 & I & \multirow{4}{*}{$\begin{array}{l}\text { bilat. } \\
\text { fr.temp.* } \\
\text { bilat. } \\
\text { fr. orbit. } \dagger \\
\text { frontal } \dagger\end{array}$} & 4 & $3 \mathrm{~m}$. & $5 y$. & \multirow{5}{*}{$\begin{array}{l}\text { lives alone, no problems } \\
\text { cohabiting, no sexual inhibition, no } \\
\text { genuine contact can be established } \\
\text { in psych. nursing home, no sexual } \\
\text { inhibition, fits of rage } \\
\text { in acute psych. ward, } \\
\text { total loss of social contact } \\
\text { in nursing home, severe emotional } \\
\text { regression }\end{array}$} \\
\hline f & 17 & I & & 4 & $5 \mathrm{~m}$. & weeks & \\
\hline f & 16 & II & & 5 & ly. & permanent & \\
\hline m & 22 & II & & 4 & $2 y$. & permanent & \\
\hline $\mathbf{m}$ & 20 & III & l.temp. & $6 \cdot 5$ & $\begin{array}{l}\text { ly. } \\
3 y . \\
6 y .\end{array}$ & weeks & \\
\hline m & 18 & II & & 4 & $\begin{array}{l}6 y . \\
9 y .\end{array}$ & weeks & lives alone, loss of social contact \\
\hline m & 19 & III & l.hemisph. & $4 \cdot 5$ & $2 y$ & weeks & \multirow{2}{*}{$\begin{array}{l}\text { lives with parents, has knocked down } \\
\text { his father three times } \\
\text { lives with parents, fits of rage }\end{array}$} \\
\hline $\mathbf{m}$ & 18 & II & $\begin{array}{l}\text { bilat. } \\
\text { fr. temp.* }\end{array}$ & -8 & $5 y$. & weeks & \\
\hline
\end{tabular}

*repeated EEG findings

tfractures of skull 
Table 5 Severe deficits at first follow-up in 24 patients with permanent or transitory dependance

\begin{tabular}{|c|c|c|c|c|c|c|c|c|c|c|}
\hline \multirow[t]{2}{*}{ Dependance } & \multirow[t]{2}{*}{$N$} & \multicolumn{2}{|c|}{$\begin{array}{l}\text { Age at } \\
\text { trauma }\end{array}$} & \multicolumn{2}{|c|}{$\begin{array}{l}\text { When seen after } \\
\text { trauma }\end{array}$} & \multicolumn{2}{|l|}{ PTA } & \multicolumn{3}{|c|}{ Number of deficits } \\
\hline & & $\begin{array}{l}\text { age } \\
(y r)\end{array}$ & $N$ & $\bar{X}$ & $\begin{array}{l}\text { months } \\
\text { range }\end{array}$ & $\bar{X}^{*}$ & $\begin{array}{l}\text { months } \\
\text { range }\end{array}$ & physical & cognitive & person. \\
\hline 1) Permanent & 12 & $\begin{array}{l}<21 \\
>21\end{array}$ & $\begin{array}{l}8 \\
4\end{array}$ & 33 & $12-50$ & $5 \cdot 8$ & $3 \cdot 5-9 \cdot 0$ & 8 & 9 & 10 \\
\hline 2) Transitory & 12 & $\begin{array}{l}<21 \\
>21\end{array}$ & $\begin{array}{l}6 \\
6\end{array}$ & 28 & $13-70$ & $4 \cdot 1$ & $2 \cdot 5-7 \cdot 0$ & 4 & 4 & 9 \\
\hline
\end{tabular}

*Significantly different at $5 \%$ level (Mann Whitney rang sum test)

Nine had signs of brainstem involvement (type II). In table 5 patients with permanent and transitory dependance are compared according to deficits at the first follow-up. It is seen that the majority had severe personality changes. However, while only one patient with transitory dependance presented a combination of severe physical, cognitive and personality problems, six patients with permanent dependance did so. Table 5 also shows that the first follow-up in average took place more than two years after the trauma and that the PTA was long in both groups, but significantly longer in cases with permanent dependance than in those with transitory. It is also worth mentioning that while six with permanent dependance had been psychotic only two with transitory dependance had been so.

\section{B. Neuropsychological sequelae}

At the first follow-up the WAIS performance scores ranged from 68-113. There was no significant difference between patients below and above the age of 21 years when injured (Mann Whitney rang sum test). Nearly all had low auditory verbal memory span, and verbal and visual learning and recall were in the majority much below the results in a non head injured control group.'

Language The frequency of communication disorders can be seen in table 6 . Regarding intelligibility dysarthria presented the most serious permanent problem. Eight were difficult to understand at the first follow-up. In one patient, who received speech therapy for a long period, articulation improved during years, but subnormal rate and increased monotony persisted and so did the motor deficits. Eleven of the $\mathbf{1 5}$ dysarthric patients had motor impairment and 12 had signs of brainstem damage.

Nine of the 19 patients who initially presented symptoms of aphasic type had focal lesions. Amnestic aphasia, verbal paraphasia and perseveration were the most common dysfunctions in the early stage and at the first follow-up. ${ }^{10}$ Analysis of speech and reading had improved in several cases at the last mentioned examination, but three patients were not able to do a test of silent reading and many among those who were considered non-aphasic, were extremely slow and/or made mistakes. Few read a newspaper. At the second follow-up many patients, whether originally aphasic or not, responded slowly and some needed repetition of questions. Subnormal rate of speaking, impaired word finding and sporadic verbal paraphasia of the semantic type, frequent pauses, the use of many set phrases, and perseveration on words and subjects were common. Aposiopesis, a condition in which a sentence is left unfinished, was often observed. Four patients, all with verified focal lesions in the left hemisphere, presented aphasic symptoms (table 6). In a man who had had an extensive subdural haematoma extreme amnestic aphasia had improved since the first follow-up five years after the trauma, but agraphia and severe dyslexia remained. The other three patients had moderate impairment with in two cases a combination of aphasia and defects of memory. Only one aphasic patient had motor deficits.

Nine patients and 17 relatives reported difficulties. Three patients complained of impaired auditory analysis, in one case problems in recognising low frequency words, especially foreign ones, which premorbidly had been familiar. Six suffered from slow speech, impaired word finding and problems in remembering what they wanted to say. The relatives of 14 patients declared that the patient easily lost track of what was said and/or forgot what was mentioned a moment ago. Three repeated themselves constantly.

At the time of the second follow-up most patients listened to the news on television, but $16(40 \%)$ never read. All but one had subnormal reading at the first follow-up.

Table 6 Disorders of communication

\begin{tabular}{lllc}
\hline & I. examination & 2.5 years & $10-15$ years \\
\hline Aphasia & 19 & 16 & 4 \\
Dysarthria & 15 & 15 & 15 \\
\hline
\end{tabular}


Memory At the first follow-up 12 patients denied memory impairment, 13 gave evasive answers, such as "I suppose I have a bit of trouble", "They say, my memory is not good" etc., and 15 declared that they had problems. The relatives reported difficulties in a little more than half the cases. However, clinical observation and cognitive assessment revealed that at least $80 \%$ had memory defects (table 7 ). At the second follow-up poor memory was described in $75 \%$ (table 7). Six patients with very severe defects were hot always orientated in the hour of the day and the day of the week. When sad, they forgot why in few minutes. In less severe cases patients often had problems in remembering names and appointments and in misplacing things. Most patients had during the years realised their memory impairment, but a few declared that they had no difficulties when asked in the interview. A moment later they spontaneously gave examples thereof.

The contingency table (7a) reveals that four patients and their relatives denied memory defects at both examinations. Three were aphasic at the first one. A woman who had had an intracerebral haematoma in the left temporal region had no general impairment 4.5 years after the injury, but severe verbal dysfunction. She was not able to recall the surnames of her two married daughters. The remaining two aphasic patients had moderate difficulties in recalling figures in a visual learning task. They both returned to normal work two and five years respectively after the trauma. The fourth patient, an unskilled labourer, had paraplegia and severe dysarthria with aphonia. Three years after the accident he started improving his schooling and passed several examinations.

\section{Psychosocial sequelae}

Behaviour The problems reported at the first and second follow-up can be seen in table 7. While lack of social contact at the former was the greatest sub-

Table 7 Problems at first and second follow-up

\begin{tabular}{lll}
\hline & $2 \cdot 5$ years & $10-15$ years \\
\hline Poor memory & $80 \%$ & $75 \%$ \\
Changes in personality and & $80 \%$ & $65 \%$ \\
emotion & $60 \%$ & $25 \%$ \\
$\quad$ childishness & $40 \%$ & $35 \%$ \\
emotional lability & $38 \%$ & $48 \%$ \\
irritability & $25 \%$ & $38 \%$ \\
restlessness & $23 \%$ & $20 \%$ \\
disturbed behaviour & $73 \%$ & $53 \%$ \\
Poor concentration & $65 \%$ & $53 \%$ \\
Slowness & $60 \%$ & $68 \%$ \\
Loss of social contact & $43 \%$ & $53 \%$ \\
Aspontaneity & $28 \%$ & $50 \%$ \\
Tiredness & $23 \%$ & $68 \%$ \\
Sensitivity distress & $20 \%$ & $55 \%$ \\
Lack of interests & &
\end{tabular}

jective burden to the patients, changes in personality and emotion presented the severest problem to the families. The spouses of the seven patients who had a divorce declared that their wives or husbands had become complete strangers. Loss of emotional control, with rapid changes between apathy and aggression, irritability, and childishness were the main complaints. The relationship between the patients and their children developed badly in all cases and the spouses considered themselves the only grownups in the families. The parents, especially the mothers of single patients, often described childishness, which in some cases initially was outstanding. When a 20-year-old man with a type II lesion returned to his parents four months after the injury, he behaved like a child of one. He followed his mother everywhere grasping her apron and constantly tried to open doors, cupboards and drawers. The young psychotic girl with the fronto-orbital fractures (table 4) presented an even more extreme regression, returning to a foetal-body pattern and behaving like a baby."

At the second follow-up several relatives reported gradual improvement in behaviour during the first five to six posttraumatic years. However, information from patients and relatives indicated that two thirds had permanent changes in personality and emotion (table 7). A statistically significant net reduction over time was found in childishness (tables 7 and 7a), but in the most severe cases, as the two referred, the patients remained dependant. Table 7a also reveals that regressive features nearly always were recognised during early stages. With reference to emotional lability, irritability, restlessness and disturbed behaviour, fluctuations took place over time (table 7a). Table $7 \mathrm{~b}$ shows that the frequence of these dysfunctions was much higher in the young than in the older ones and a significant difference was present in the last three mentioned problems (when tested by means of Chi squared emotional lability also reached significance, but without Yates correction). Furthermore practically all late deficits, that is after the first follow-up, occurred in the young (table 7a). Disturbed behaviour was the most infrequent change of all, but was viewed seriously of the relatives. A fifth had permanent troubles, such as aggressiveness and lack of sexual inhibition, including a case of promiscuity. All were in the age group 15-21 when injured (table 7b). Among the five who recovered (table 7a), four had been verbally aggressive and one, a woman of 37 when injured, had been hypersexual. She had a type I lesion with signs of bitemporal lesions (permanent EEG findings) and a PTA of 5 months. She was married and had children, but was divorced. At the second follow-up she had for some years had a 
Table 7a Contingency tables

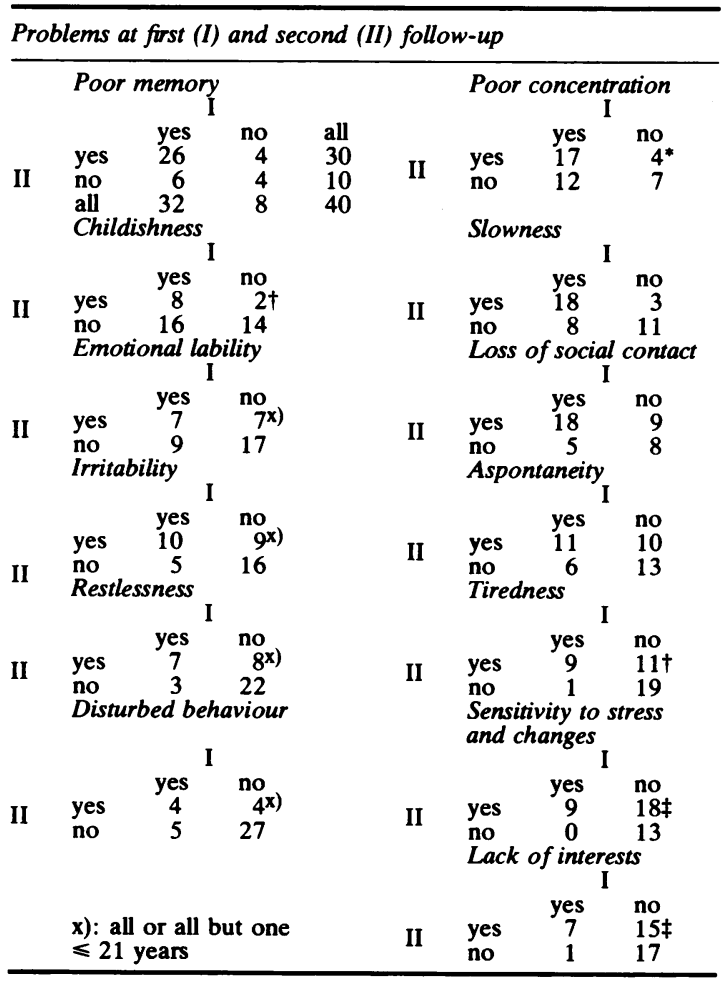

McNemar's test for significance of changes. *significantly different at $5 \%$ level, † significantly different at $1 \%$ level, ¥significantly different at $1 \%$ level

sexual relationship with a partner at the age of her father. She spontaneously declared that she, in deep contrast to her premorbid life, had had no interests apart from her sexual needs for the first five posttraumatic years.

A statistically significant net reduction was present in impairment of concentration (table 7a). It is, however, important to bear in mind that very few involved themselves in intellectual tasks, such as reading a book. A statistically significant net increase was found in tiredness, lack of interests, and sensitivity distress, and improvement practically never occurred. Tiredness was the only problem that was most frequent among older patients, no difference between the age groups was seen in lack of interests, and sensitivity distress was most common in the young (table 7b). When severe, the last mentioned change created troubles in daily life. A young man with a PTA of 7 months thus kept a rigid programme, bathing, eating, reading his newspaper and taking his routine walk at exactly the same time every day. It is also important to mention the moderate increase in aspontaneity and the high fre- quency of permanent lack of initiative in the young (tables 7 and $7 b$ ).

At the second follow-up two thirds had no contact outside the close family (table 7), and social isolation remained the patients' severest burden. Hardly any had been able to keep in touch with premorbid friends and very few made but casual acquaintances ("people I meet in the bus" etc.). Several preferred to make friends with old people, since they were kind and patient. At least three had or had had sexual relationships with partners at the age of their parents.

In contrast to the majority, eight had but few problems. Tiredness was the most frequent complaint. Half the patients had a PTA exceeding 3 months.

Work capacity In the years between the follow-up examinations 12 patients had attended courses at a "hoejskole", that is a boarding school for grownups, and some did so twice.

At the second follow-up 37 (93\%) had a disablement pension. Only three had or had had full-time work (table 8 ). The physically strong, but severely aphasic man who had had a left subdural haematoma, mentioned before, had twenty jobs or so in the first five posttraumatic years. He then became a truck-driver and was still employed in the firm ten years later. He was not able to write his timesheet. A woman, aged 24 when injured with a type I lesion and a PTA of 3 months, was considered severely regressive two years after the accident, in which she lost her husband and only child. She started working as an unskilled labourer six years after the injury, but had to stop two years later after childbirth. Finally a man, aged 17 years when injured with a left temporal lesion (type III) and a PTA of 2.5 months, returned to his job as a baker's apprentice. He finished his training, but left the job and worked as an unskilled labourer for several years. It is also seen in table 8 that two had part-time work. The one, a woman with a PTA of one month, worked as a clerk and had no complaints except tiredness, the other, a male piano-tuner, had signs of severe memory impairment, but had apparently not lost his professional skill.

While at the first follow-up very few had been in contact with local rehabilitation centres, 23 had been so at the second. One patient, a farmer, had been trained as a book-keeper, but was not employed. The patient with the rigid programme of the day had tried several jobs at a very basic level for eight years, but all in vain. Seven had got paid sheltered work (table 8). One, a man of 44 when injured, had had a left subdural and epidural haematoma and a PTA of 5 months. He remained 
Table $7 \mathrm{~b}$ Frequency of problems in patients with deficits at second follow-up

\begin{tabular}{|c|c|c|c|c|}
\hline \multirow[t]{2}{*}{ Problem } & & \multicolumn{2}{|c|}{ Age at trauma } & \multirow[t]{2}{*}{ Total no. } \\
\hline & & $\begin{array}{l}\leqslant 21 y . \\
\text { no. } 23\end{array}$ & $\begin{array}{l}>21 y \\
\text { no. } 17\end{array}$ & \\
\hline Poor memory & $\begin{array}{l}\text { A: present } \\
\text { B: absent }\end{array}$ & $\begin{array}{r}18(78 \%) \\
5(22 \%)\end{array}$ & $\begin{array}{r}12(71 \%) \\
5(29 \%)\end{array}$ & $\begin{array}{l}30 \\
10\end{array}$ \\
\hline Childishness & A: & $7(30 \%)$ & $3(18 \%)$ & 10 \\
\hline & B: & $16(70 \%)$ & $14(82 \%)$ & 30 \\
\hline Emotional lability & A: & $11(48 \%)$ & $3(18 \%)$ & 14 \\
\hline & B: & $12(52 \%)$ & $14(82 \%)$ & 26 \\
\hline Irritability & A: & $15(65 \%)$ & $4(24 \%)$ & $19^{*}$ \\
\hline & B: & $8(35 \%)$ & $13(76 \%)$ & 21 \\
\hline Restlessness & A: & $13(57 \%)$ & $2(12 \%)$ & $15 \dagger$ \\
\hline & B: & $10(43 \%)$ & $15(88 \%)$ & 25 \\
\hline Disturbed behaviour & A: & $8(35 \%)$ & $0\left(0^{*}\right)$ & $8^{*}$ \\
\hline & B: & $15(65 \%)$ & $17(100 \%)$ & 32 \\
\hline Poor concentration & A: & $14(61 \%)$ & $7(41 \%)$ & 21 \\
\hline & B: & $9(39 \%)$ & $10(59 \%)$ & 19 \\
\hline Slowness & A: & $13(57 \%)$ & $8(47 \%)$ & 21 \\
\hline & B: & $10(43 \%)$ & $9(53 \%)$ & 19 \\
\hline Loss of social contact & A: & $17(74 \%)$ & $10(59 \%)$ & 27 \\
\hline & B: & $6(26 \%)$ & $7(41 \%)$ & 13 \\
\hline Lack of spontaneity & A: & $15(65 \%)$ & $6(35 \%)$ & 21 \\
\hline Tiredness & B: & $8(35 \%)$ & $11(65 \%)$ & 19 \\
\hline Tiredness & $\begin{array}{l}\text { A: } \\
\text { B: }\end{array}$ & $10(43 \%)$ & $10(59 \%)$ & 20 \\
\hline Sensitivity, distress & A: & $18(78 \%)$ & $9(53 \%)$ & 27 \\
\hline & B: & $5(22 \%)$ & $8(47 \%)$ & 13 \\
\hline Lack of interests & A: & $13(57 \%)$ & $9(53 \%)$ & 22 \\
\hline & B: & $10(43 \%)$ & $8(47 \%)$ & 18 \\
\hline
\end{tabular}

Fisher's exact test for significance of difference in frequency in age groups.

* significantly different at $5 \%$ level

tsignificantly different at $1 \%$ level

Table 8 Work capacity at 1 st and 2 nd follow-up

\begin{tabular}{|c|c|c|c|}
\hline & \multicolumn{2}{|c|}{ No. of patients } & \multirow{2}{*}{$\begin{array}{l}\text { Patients entering } \\
(+) \text { or leaving } \\
(-) \text { group }\end{array}$} \\
\hline & $2.5 y r$. & $10-15 y r$. & \\
\hline $\begin{array}{l}\text { Full-time } \\
\text { Part-time } \\
\text { Retrained, unemployed } \\
\text { Paid sheltered work } \\
\text { Attending courses } \\
\text { Homeminders }\end{array}$ & $\begin{array}{l}2 \\
4 \\
0 \\
3 \\
1 \\
1\end{array}$ & $\begin{array}{l}3 \\
2 \\
1 \\
7 \\
2 \\
3\end{array}$ & $\begin{array}{r}-2 \\
+1 \\
-1+5 \\
-1+2 \\
+2\end{array}$ \\
\hline
\end{tabular}

severely aphasic for many months, but started working in the Royal Library two years after the trauma. He was extremely orderly and had at the second follow-up the responsibility of half a million index cards. ${ }^{12}$ Another patient, a man of 20 when injured, with a type II lesion and a PTA of 6 months had slow waves down to $1.0 \mathrm{~Hz}$ over both hemispheres a week after the accident. Three years later the WAIS performance score was 68 . At the time of the second follow-up he had been working the past four years as a gardener's assistant at a hospital. His employer praised his behaviour, industry and initiative. Two patients had such severe motor impairment that sheltered work was not possible. They improved their schooling (table 8). One, a man with parap- legia, has been mentioned. The case of the other, a locksmith, aged 19 when injured, is thoughtprovoking. He had a type II lesion and did not respond verbally or non-verbally to speech until four months after the trauma. The PTA was 7 months. There was severe hypertonia in both arms and legs and contractures. Operations were not successful. One year after the accident he was totally dependant with dysarthria, severe emotional regression but only moderate cognitive deficits. He was in a nursing home for three years without much improvement. According to his own explanation he then started asking himself, whether he wanted to spend the rest of his life in this way. A year later he went to a "hoejskole" and stayed there for a year. At second follow-up he lived alone and had taught himself to walk indoors. He hoped to obtain "studentereksamen", that is admission to university and had passed in half the subjects, but had taken much longer time than normally. He had many friends.

It is also worth mentioning that three women were able to manage their housekeeping and shopping themselves. One with permanent aphasia had no trouble either at the first follow-up, the remaining two were at that time unable to do any piece of work on their own. They were among those who were divorced. 


\section{Discussion}

In the present investigation on late outcome in very severe head trauma no one escaped permanent sequelae. More than a quarter remained dependant and practically all received disablement pension. The worse overall outcome was found in cases with brainstem involvement and/or severe verified anterior lesions.

The frequency of motor impairment was much higher in this sample than in cases with severe head injury but a shorter PTA. ${ }^{2}$ Several recovered during the first year or two, but a third remained severely disabled. The presence and degree of brainstem damage was crucial. This was also the case regarding dysarthria, the most serious permanent disorder of communication in the material. Recovery was better in aphasia, at least as far as functional communication is concerned, but few, if any, regained their premorbid language abilities. In the course of time the discrepancy between aphasic and nonaphasic patients frequently diminished. The sequelae of severe diffuse neuronal damage, such as defects of memory and concentration and slowness became predominant features and the linguistic deficits could often be described as instances of general mental impairment..$^{13}$ Sarno $^{14}$ found in a recent investigation of patients with closed head trauma that no one escaped some degree of verbal dysfunction. The results in the present late study indicate that language impairment, at least in very severe cases, is permanent, but not often in form of aphasia per se. In contrast to the findings of McKinlay et $a l^{6}$ disorders of communication, especially dysarthria, often presented severe problems to patients and relatives.

Psychoses only occurred in cases with a PTA of more than 3 months and often in connection with verified anterior lesions and/or severe left hemisphere damage. ${ }^{15}$ Most patients remained dependant.

Changes in behaviour continued to be a most serious burden and though some fluctuation in symptoms took place, the frequency did not change positively, except in childishness. The absence of the problem at the first follow-up was a good predictor that it would still be absent in later stages, but its presence at the first follow-up was not a good predictor of its presence later on. The opposite was the case in tiredness, lack of interests and sensitivity distress, with the presence of the symptoms at first follow-up being a very good predictor of their presence later on, but their absence at first follow-up being a poor predictor of their absence in later stages.

While a spectrum of intolerable problems was reported in married patients at the first follow-up, the young had the greatest frequency of permanent changes, in particular in personality and emotion. The majority of late problems was also found in this group. McKinlay et $a l^{6}$ have reported similar late increase of emotional difficulties in head injured patients during the first posttraumatic year. Their cases were severe, but PTA was generally much shorter than in the present sample and the results may, in spite of the different lapse of time, reflect the same mechanisms. It is not possible to prove whether the late dysfunctions were direct results of the trauma or reactions to disabilty. Clinical observation at the first follow-up suggested that some relatives, especially parents, only slowly came to accept the full extent of changes. ${ }^{7}$ The different reactions of spouses and parents were striking, the former expressing only too realistic views, the latter the opposite. As to the patients themselves lack or demise of insight were generally more pronounced and more long-lasting in the young than in the older patient. As assessed by the PTA there was no statistically significant difference in the severity of cerebral injury in the two age groups. The young had the greater number of severe anterior lesions, but the focal damage was in all cases accompanied by very severe diffuse neuronal damage. The results in this study may indicate that the immature personality is particularly vulnerable in severe head trauma.

Loss of social contact remained the patients' most disabling handicap in daily life. Not only patients but also families became isolated. Great permanent difficulties were described in cases, where parents lived with a severely disabled son. The relationship between father and son easily became strained and the family became isolated, because the siblings stopped visiting. ${ }^{16}$

Studies have indicated that the greatest recovery occurs in the first six months, ${ }^{17}$ but that there is a varying pattern in the individual patients ${ }^{18}$ and that improvement is possible as long as three years after the injury. ${ }^{3}$ In the present investigation many examples have been given of long-term improvement in functional state. It is especially remarkable that half the patients who could not be left alone two years or more after the accident became independent during the following years. Several in the sample regained at least some work capacity, but generally not until years after the injury. The late results thus indicate that though the patient with very severe head trauma may remain disabled, improvement in psychosocial functions can continue for several years.

This investigation was supported by a grant from the Danish Ministry of Social Affairs no. 4.10.53.02. 
I remember with deep gratitude the late Professor Erik Skinhøj for inspiration and crucial support in the study of patients with severe head trauma. Thanks are due to Dr Neil Brooks for helpful criticism of this paper.

\section{References}

' Miller H, Stern G. The long-term prognosis of severe head injury. Lancet 1965;1:225-9.

${ }^{2}$ Fahy TJ, Irving MH, Millac P. Severe head injuries: a six year follow-up. Lancet 1967;2:475-9.

${ }^{3}$ Najenson T, Mendelson L, Schechter I, David C, Mintz N, Grosswasser Z. Rehabilitation after severe head injury. Scand J Rehab Med 1974;6:5-14.

${ }^{4}$ London PS. Some observations on the course of events after severe injury of the head. Ann R Coll Surg Engl 1967;41:460-79.

${ }^{5}$ Bond MR. Assessment of psychosocial outcome after severe head injury. In: Outcome of Severe Damage to the CNS. Ciba Foundation Symposium 1975; 34: 141-53.

- McKinlay WW, Brooks DN, Bond MR, Martinage DP, Marshall MM. The short-term outcome of severe blunt head injury as reported by relatives of the injured persons. J Neurol Neurosurg Psychiatry 1981;44:527-33.

${ }^{7}$ Brooks DN, McKinlay WW. Personality and behavioural change after severe blunt head injury-a relative's view.J Neurol Neurosurg Psychiatry 1983;46:336-44.
${ }^{8}$ Thomsen IV. The patient with severe head injury and his family. Scand J Rehab Med 1974;6:180-3.

${ }^{9}$ Thomsen IV. Verbal learning in aphasic and non-aphasic patients with severe head injuries. Scand J Rehab Med 1977;9:73-7.

${ }^{10}$ Thomsen IV. Evaluation, outcome and treatment of aphasia in patients with severe head injuries. In: Sarno MT, Höök O, eds. Aphasia. Assessment and Treatment. Stockholm: Almqvist \& Wiksell, 1980:181-5.

"Thomsen IV, Skinhøj E. Regressive language in severe head injury. Acta Neurol Scand 1976;54:219-26.

12 Thomsen IV. Neuropsychological treatment and long time follow-up in an aphasic patient with very severe head trauma. J Clin Neuropsychol 1981;3:43-51.

${ }^{13}$ Levin HS, Grossman RG, Kelly PJ. Aphasic disorder in patients with closed head injury. $J$ Neurol Neurosurg Psychiatry 1976;39:1062-70.

${ }^{14}$ Sarno MT. The nature of verbal impairment after closed head injury. J Nerv Ment Dis 1980;168:685-92.

${ }^{15}$ Lishman WA. The psychiatric sequelae of head injury: a review. Psychol Med 1973;3:304-18.

${ }^{16}$ Oddy M, Humphrey M. Social recovery during the year following severe head injury. J Neurol Neurosurg Psychiatry 1980;43:798-802.

${ }^{17}$ Bond MR, Brooks DN. Understanding the process of recovery as a basis for the investigation of rehabilitation for the brain injured. Scand J Rehab Med 1976;8:127-33.

${ }^{18}$ Brooks DN, Aughton ME. Cognitive recovery during the first year after severe blunt head injury. Int Rehab Med 1979;1:166-72. 